\title{
BDNF haploinsufficiency induces behavioral endophenotypes of schizophrenia in male mice that are rescued by enriched environment
}

\author{
Mahmoud Harb', Justina Jagusch', Archana Durairaja', Thomas Endres², Volkmar Leßmannn ${ }^{2,3}$ and Markus Fendt (1) ${ }^{1,3}$
}

\begin{abstract}
Brain-derived neurotrophic factor (BDNF) is implicated in a number of processes that are crucial for healthy functioning of the brain. Schizophrenia is associated with low BDNF levels in the brain and blood, however, not much is known about BDNF's role in the different symptoms of schizophrenia. Here, we used BDNF-haploinsufficient $\left(\mathrm{BDNF}^{+/-}\right)$mice to investigate the role of BDNF in different mouse behavioral endophenotypes of schizophrenia. Furthermore, we assessed if an enriched environment can prevent the observed changes. In this study, male mature adult wild-type and $\mathrm{BDNF}^{+/-}$mice were tested in mouse paradigms for cognitive flexibility (attentional set shifting), sensorimotor gating (prepulse inhibition), and associative emotional learning (safety and fear conditioning). Before these tests, half of the mice had a 2-month exposure to an enriched environment, including running wheels. After the tests, BDNF brain levels were quantified. BDNF ${ }^{+/-}$mice had general deficits in the attentional set-shifting task, increased startle magnitudes, and prepulse inhibition deficits. Contextual fear learning was not affected but safety learning was absent. Enriched environment housing completely prevented the observed behavioral deficits in BDNF ${ }^{+/-}$mice. Notably, the behavioral performance of the mice was negatively correlated with BDNF protein levels. These novel findings strongly suggest that decreased BDNF levels are associated with several behavioral endophenotypes of schizophrenia.

Furthermore, an enriched environment increases BDNF protein to wild-type levels and is thereby able to rescue these behavioral endophenotypes.
\end{abstract}

\section{Introduction}

Schizophrenia is a neuropsychiatric disorder associated with life-long disabilities and a reduced life expectancy ${ }^{1}$. Typically, the symptoms appear in adolescence or early adulthood and include positive symptoms like hallucinations and delusions, negative symptoms like social withdrawal and lack of motivation, and cognitive symptoms like difficulties in memory, attention, and executive functions ${ }^{1}$. Schizophrenia is a neurodevelopmental disorder, caused by a combination of genetic susceptibility

\footnotetext{
Correspondence: Volkmar Leßmann (volkmar.lessmann@med.ovgu.de) or Markus Fendt (markus.fendt@med.ovgu.de)

${ }^{1}$ Institute for Pharmacology and Toxicology, Otto-von-Guericke University Magdeburg, Magdeburg, Germany

${ }^{2}$ Institute of Physiology, Otto-von-Guericke University Magdeburg, Magdeburg, Germany

Full list of author information is available at the end of the article
}

and environmental insults ${ }^{2}$. Furthermore, alterations in the inflammatory and immune systems are involved in the etiopathogenesis of schizophrenia ${ }^{3,4}$. All these factors induce or contribute to molecular, cellular, and structural changes in the brain, which eventually cause the symptoms of schizophrenia ${ }^{5}$.

Some neuropathological features of schizophrenia are correlated with reduced levels of brain-derived neurotrophic factor (BDNF). BDNF belongs to the protein family of neurotrophins and is secreted by neurons ${ }^{6,7}$. BDNF is involved in the survival, development, and differentiation of neurons and is crucial for synaptic plasticity ${ }^{6,8-10}$. A plethora of findings demonstrated a pivotal role of BDNF in learning and memory ${ }^{11-15}$. Studies using heterozygous BDNF-deficient mice and mice carrying the val66met BDNF polymorphism that reduces activity-dependent

\section{(c) The Author(s) 2021}

\footnotetext{
(c) Open Access This article is licensed under a Creative Commons Attribution 4.0 International License, which permits use, sharing, adaptation, distribution and reproduction cc) in any medium or format, as long as you give appropriate credit to the original author(s) and the source, provide a link to the Creative Commons license, and indicate if changes were made. The images or other third party material in this article are included in the article's Creative Commons license, unless indicated otherwise in a credit line to the material. If material is not included in the article's Creative Commons license and your intended use is not permitted by statutory regulation or exceeds the permitted use, you will need to obtain permission directly from the copyright holder. To view a copy of this license, visit http://creativecommons.org/licenses/by/4.0/.
} 
BDNF secretion ${ }^{16}$ show deficits in learning and memory and suggest that BDNF is involved in different neuropsychiatric disorders ${ }^{17-21}$. Several lines of evidence support an important role of BDNF in schizophrenia: first, schizophrenic patients show lower BDNF levels in the blood $^{22}$ and cerebrospinal fluid ${ }^{23}$, as well as in different brain areas ${ }^{24-27}$. Second, BDNF blood levels of drug-naive first-episode patients are negatively correlated with positive symptoms $^{28,29}$. Third, the single-nucleotide Val66Met polymorphism in the BDNF gene, which is considered to reduce activity-dependent $\mathrm{BDNF}$ secretion ${ }^{16}$, might be associated with increased susceptibility to schizophrenia, as well as with particular symptoms and the onset age of schizophrenia ${ }^{30-35}$ (but see ref. ${ }^{36}$ ). Based on these and other findings, more research on how BDNF affects symptom presence and intensity and/or therapeutic responsiveness is demanded, with the final aim to also foster novel, BDNF-associated treatment approaches ${ }^{30,37}$.

A very useful animal model to investigate the role of BDNF in behavioral endophenotypes of schizophrenia is the BDNF-haploinsufficient $\left(\mathrm{BDNF}^{+/-}\right)$mouse strain that has an $\sim 50 \%$ reduction in BDNF expression ${ }^{38}$. In mice, several behavioral endophenotypes of schizophrenia, such as sensorimotor gating deficits or impaired executive functions ${ }^{39}$, can be measured with experimental tests such as prepulse inhibition (PPI) of the startle response $e^{40,41}$ or the attentional set-shifting task (ASST), a measure for cognitive flexibility ${ }^{42}$. Of interest is also fear and safety learning ${ }^{43,44}$ since associative learning is impaired in schizophrenia patients ${ }^{45,46}$ and recent studies found deficient safety learning in these patients ${ }^{47,48}$. A previous study reported that PPI is not affected in young (13 weeks old) $\mathrm{BDNF}^{+/-}$mice ${ }^{49}$. Regarding cognitive flexibility, reversal learning but not strategy shifting was impaired in young (8 weeks) $\mathrm{BDNF}^{+/-}$mice ${ }^{50}$. However, several studies demonstrated that some behavioral deficits appear first in mature adult $\mathrm{BDNF}^{+/-}$mice ${ }^{51-54}$. The latter is critical since mature adultness (3-6 months in mice, $20-30$ years in humans ${ }^{55,56}$ ) is the usual age of the first admission for schizophrenia ${ }^{28,29,57}$. To the best of our knowledge, mature adult $\mathrm{BDNF}^{+/-}$mice ( $\geq 5$ months) were not tested for behavioral endophenotypes of schizophrenia so far.

Thus, the aim of this study was to investigate the role of BDNF in mouse behavioral endophenotypes of schizophrenia. Male mature adult (i.e., 5-6-months old) $\mathrm{BDNF}^{+/-}$mice and their wild-type littermates $\left(\mathrm{BDNF}^{+/+}\right.$ mice) were submitted to the following schizophreniarelevant behavioral tests: (a) ASST as a measure for cognitive flexibility, (b) PPI of the acoustic startle response as a measure for sensorimotor gating, and (c) safety and contextual fear conditioning as measures of associative memory processes. Since behavioral deficits and BDNF brain levels in $\mathrm{BDNF}^{+/-}$mice can be rescued by housing them in enriched environmental conditions ${ }^{58,59}$, the second set of mice was exposed to enriched environment (EE) for 2 months and subsequently submitted to the same behavioral tests. After completing all behavioral tests, BDNF levels of several brain areas were analyzed. Our hypothesis was that mature adult $\mathrm{BDNF}^{+/-}$mice express behavioral endophenotypes of schizophrenia that can be prevented by EE exposure.

\section{Materials and methods \\ Animals}

In this study, we used male heterozygous BDNF knockout mice $\left(\mathrm{BDNF}^{+/-}\right.$mice, $\left.\mathrm{Bdnf} \mathrm{f}^{\mathrm{tm} 1 \mathrm{Tbn}}\right)$, which were generated by replacing a fragment of the BDNF proteincoding exon with a selection marker ${ }^{38}$. Constitutive BDNF knockout mice were independently generated in different laboratories with all strains showing an identical phenotype ${ }^{38,60-62}$ and are generally accepted mouse models to study the consequences of chronically reduced BDNF protein levels ${ }^{51-53,63-69}$. The $\mathrm{BDNF}^{+/-}$mice from these independently generated mouse strains express $\sim 50 \%$ of wild-type BDNF protein levels in all tested brain areas throughout their lives. Consequently, they show deficits in synaptic plasticity in the hippocampus, neocortex, and amygdala ${ }^{38,65,70-74}$, and age-dependent memory deficits, e.g., in hippocampus-dependent and amygdala-dependent learning tasks ${ }^{51-53,63,67,75}$.

The $\mathrm{BDNF}^{+/-}$and $\mathrm{BDNF}^{+/+}$mice used in the present study were offspring of $\mathrm{BDNF}^{+/-} / \mathrm{BDNF}^{+/+}$breeding pairs from a line bred on a C57BL/6J background ( $>10$ generations). The mice's age at the beginning of the behavioral test was 5-6 months. The mice were kept in genotyped mixed groups of 2-6 animals per cage in a humidity- and temperature-controlled room (50-55\%, $22 \pm 2{ }^{\circ} \mathrm{C}$ ) with a light cycle of $12 \mathrm{~h}$ on/off periods (lights on at 6:00 a.m.). Water and food were available ad libitum. All behavioral tests were carried out during the light phase (10:00 a.m.-4:00 p.m.). The experiments were performed in accordance with international ethical guidelines for the use of animals in experiments (2010/63/ $\mathrm{EU})$ and were approved by the local authorities (Landesverwaltungsamt Sachsen-Anhalt, Az.42505-2-1172 UniMD).

\section{Experimental procedure}

The experimental procedure is outlined in Fig. 1. In total, 100 mice were used. Four different batches of mice were reared under standard housing conditions. At an age of 3-4 months, two of these batches were submitted to EE. Two months later, one batch of each housing condition was trained and tested in the ASST (standard housing: $10 \mathrm{BDNF}^{+/+}$mice, $8 \mathrm{BDNF}^{+/-}$mice; enriched environment: $9 \mathrm{BDNF}^{+/+}$mice, $11 \mathrm{BDNF}^{+/-}$mice). Since ASST was associated with food restriction, the body 


$10 \mathrm{BDNF}+/+$
$8 \mathrm{BDNF}+/-$

weight of these mice was controlled. The other batch of each housing condition was first tested for its startle reactivity and one day later for PPI (standard housing: 16 $\mathrm{BDNF}^{+/+}$mice, $18 \mathrm{BDNF}^{+/-}$mice; enriched environment: $17 \mathrm{BDNF}^{+/+}$mice, $11 \mathrm{BDNF}^{+/-}$mice). Then, they were submitted to safety and contextual fear conditioning. Animal stress during the behavioral experiments was minimized by using minimally stressful stimuli, trained experimenters, and only short periods outside the home cage. After the behavioral experiments, mice were euthanized by decapitation under light isoflurane anesthesia and the brains were collected for the analysis of BDNF levels.

\section{Standard housing and enriched environment (EE)}

Standard housing was performed in Makrolon Type III cages $(38 \times 22 \times 15 \mathrm{~cm})$ each equipped with one cardboard tunnel and paper tissue. EE housing took place in Makrolon Type IV cages $(56 \times 33 \times 29 \mathrm{~cm})$ each equipped with 2-3 cardboard tunnels, several paper tissues, wood gnawing blocks, and a mouse enclosure. For voluntary running, two running wheels (Fast-Trac, Plexx BV, Elst, The Netherlands) mounted on mouse igloos were placed in each cage. Every week, the cages were cleaned, the tissues renewed, and the enrichment objects newly arranged.

\section{Attentional set-shifting task (ASST)}

Custom-built boxes $(41 \times 22 \times 24 \mathrm{~cm})$ consisting of a waiting area and-separated by transparent sliding doors - two further compartments (testing area) equipped with plastic bowls $(5-\mathrm{cm}$ diameter, $3-\mathrm{cm}$ high) were used $^{76}$. The bowls could be individually odorized and filled with different digging media. One particular odor or digging medium, respectively, was associated with a Choco Rice reward (ca. 20 mg, Nordgetreide GmbH \& Co. $\mathrm{K}$, Lübeck, Germany) underneath the digging medium. For the task, different exemplars of the stimulus dimensions "odor" and "digging medium" were used. The "odor" stimuli consisted of different odorants (e.g., citral, eucalyptol, s- $(+)$-carvone, $\mathrm{R}-(+)$-carvone, valeric acid, and 2phenylethanol, Sigma-Aldrich/Merck, Darmstadt, Germany) that were 1:20 dissolved in paraffin oil. In total, $30 \mu \mathrm{l}$ of the solution were put on a small filter paper that was fixed on the bowls in the testing area. The "digging medium" stimuli consisted of wooden pearls of different sizes and colors (6- or 10-mm diameter, green, yellow, and brown; Aduis GmbH, Kiefersfelden, Germany). A further bowl with tap water was located in the waiting area.

Before the actual ASST, the mice were food-restricted ( $2 \mathrm{~g}$ food/day/animal) with the aim of reaching ca. $85 \%$ of the body weight with ad libitum feeding. Three days before the task, a habituation/prelearning period started. On the first day of this period, two bowls filled with bedding material and some reward were placed in the home cage of the mice. On the second day, all mice of a home cage were put into the experimental box equipped with the bowls (again filled with bedding material and some reward) and allowed to freely explore the box for $45 \mathrm{~min}$. On the third day, the mice were individually put into the boxes. They had to collect rewards that were first put on the bedding material in the bowls but then gradually deeper in the bedding material with the aim that the mice learn to dig for the reward. The mice needed 30-60 min to learn the latter. On the next day, the last training stage occurred. Now, only one bowl was baited with reward (now always placed underneath the bedding material), and two different odorants were added to the two bowls. The mice now had to learn that one of two odorants predicted the reward (simple discrimination), however, the reward could be placed in both compartments (pseudorandomized from trial to trial). Each trial started with placing the mouse in the waiting area. Then, the sliding doors to the testing area were opened. The first two trials were free trials, i.e., the mouse had the possibility to dig in both bowls even if it dug in the unrewarded bowl first. From the third trial on, the sliding doors were closed as soon as the mouse started to dig in one bowl. Digging, retrieving, and eating the reward in the rewarded bowl was considered as a successful trial, digging in the unrewarded bowl as an unsuccessful trial. After each trial, the mouse was guided to the waiting area. Then, the two bowls were replaced by new bowls (reward location was randomized) and the next trial started. The simple discrimination phase was considered as passed if the criterion of six consecutive correct trials was made. Then, the ASST task immediately started. Two new odors were used 
and, importantly, a second stimulus dimension was now added: as digging material within the bowls, wooden pearls of different sizes and colors were used. In the subsequent phase, one of the two odors predicted the reward, while the digging material was irrelevant, i.e., not reward-associated (compound discrimination). Localization of the rewarded bowl in the two compartments was pseudorandomized. After reaching the criterion of six consecutive correct trials, the contingencies of the two odor cues were changed, i.e., the previously rewardassociated odor was not reward-associated anymore, and vice versa (reversal 1). After reaching the criterion, mice were put back in the home cage. One day later, the next phase started (intradimensional shift). Two new odors and two new digging materials were used, however, still one of the odors was reward-associated while the digging materials were not relevant. After completion, contingencies were changed again (reversal 2). Then two new odors and two new digging materials were used but notably, now the digging material became relevant, i.e., reward-associated cue, whereas the odors became irrelevant (extradimensional shift). After completion, contingencies were changed a third time (reversal 3).

\section{Acoustic startle response and prepulse inhibition (PPI)}

A startle system (SR-LAB, San Diego Instruments, San Diego, USA) with eight chambers $(35 \times 35 \times 35 \mathrm{~cm})$ was used for measuring the startle response and its inhibition by prepulses ${ }^{77}$. For the experiments, the animals were put inside transparent horizontal Plexiglas cylinders $(4-\mathrm{cm}$ diameter, $10-\mathrm{cm}$ length) inside these chambers. Motionsensitive transducers for detecting the startle response were mounted underneath the cylinders. The output signal of these transducers was digitized (sampling rate: $1 \mathrm{kHz}$ ) and stored on a computer. The mean transducer output $10-30 \mathrm{~ms}$ after startle stimulus onset was used as startle magnitude (arbitrary units). White background noise (55-dB SPL) was generated by high-frequency loudspeakers mounted in the center of the ceiling of the test chambers.

First, the mice were tested for their startle response to different startle stimulus intensities: after an acclimatization period of $5 \mathrm{~min}$ (only background noise), three blocks with eight trials each were presented. In each of the blocks, all eight possible stimulus intensities were presented in a pseudorandomized order (78-, 84-, 90-, 96-, 102-, 108-, 114-, and 120-dB SPL). The intertrial intervals were $30 \mathrm{~s}$. One day later, PPI of the startle response was tested. After an acclimatization period of $5 \mathrm{~min}$ (only background noise), 12 startle stimuli were presented in order to habituate the animals. Afterward, six blocks with six trials each were presented. In each of the blocks, all six possible trial types were presented in a pseudorandomized order (startle stimulus without prepulse, startle stimulus with prepulses of $2,4,8,12$, or 16-dB SPL above background noise). All prepulses had a duration of $20 \mathrm{~ms}$ and preceded the startling stimulus by $100 \mathrm{~ms}$ (onset to onset). The intertrial intervals were $20 \mathrm{~s}$. PPI for each prepulse intensity was calculated for each individual animal according to the following formula: PPI $=$ (mean startle magnitude without prepulse-mean startle magnitude with prepulse)/(mean startle magnitude without prepulse/ 100).

\section{Safety and contextual fear conditioning}

A computerized fear-conditioning system (TSE Systems, Bad Homburg, Germany) consisting of four identical transparent Perspex boxes $(46 \times 46 \times 32 \mathrm{~cm})$ was used. The boxes were surrounded by infrared animal detection sensor frames and located in a soundattenuating chamber provided with loudspeakers for the acoustic stimuli (background noise of 55-dB SPL and the tone stimuli for safety conditioning), light sources (continuous illumination of ca. 10 lux), and a ventilation fan. The floor of the boxes consisted of removable stainlesssteel grids (bars: 4-mm diameter, distance: $9 \mathrm{~mm}$ ), which were connected to a shock unit and able to deliver foot shocks. Delivery of all stimuli was controlled by the TSE Fear Conditioning software. Movements of the animals were detected by the infrared sensors (distance: $14 \mathrm{~mm}$ ). Freezing behavior was defined as no infrared beam crosses for more than $1 \mathrm{~s}$. This automatic measurement of freezing in the TSE fear conditioning system was previously validated by demonstrating a high correlation with observer scoring of freezing ${ }^{78,79}$.

On the first day, mice were habituated to the conditioning boxes with a steel grid floor and the perspective safety CS (10-kHz tone, $85-\mathrm{dB}$ SPL, $30 \mathrm{~s})$. On the next two days, two safety conditioning sessions were performed ${ }^{44}$. The aversive unconditioned stimulus was a scrambled electric stimulus via the floor grid $(0.4 \mathrm{~mA}, 2 \mathrm{~s})$. In each of both conditioning sessions, the mice were exposed to five explicit unpairing of the tone stimulus (mean interval: $2 \mathrm{~min}$, range: $1.5-2.5 \mathrm{~min}$ ) and the unconditioned stimulus (Supplementary Fig. 1). Explicit unpairing means that the foot shocks were pseudorandomly presented between two tone presentations with a minimal time distance of $30 \mathrm{~s}$ to the previous and the next tone. With this protocol, the mice should learn that they can receive foot shocks in the conditioning context (i.e., contextual fear conditioning) but that the tone CS predicts a time when there will be no shock (i.e., cued safety conditioning). Thirty seconds after the last tone presentation, the mice were returned to their home cage. On the fourth day, a retention test of contextual fear and of conditioned safety was performed. The mice were placed into the conditioning boxes and after $30 \mathrm{~s}, 5$ tone stimuli were presented at an interstimulus interval of $1 \mathrm{~min}$. 


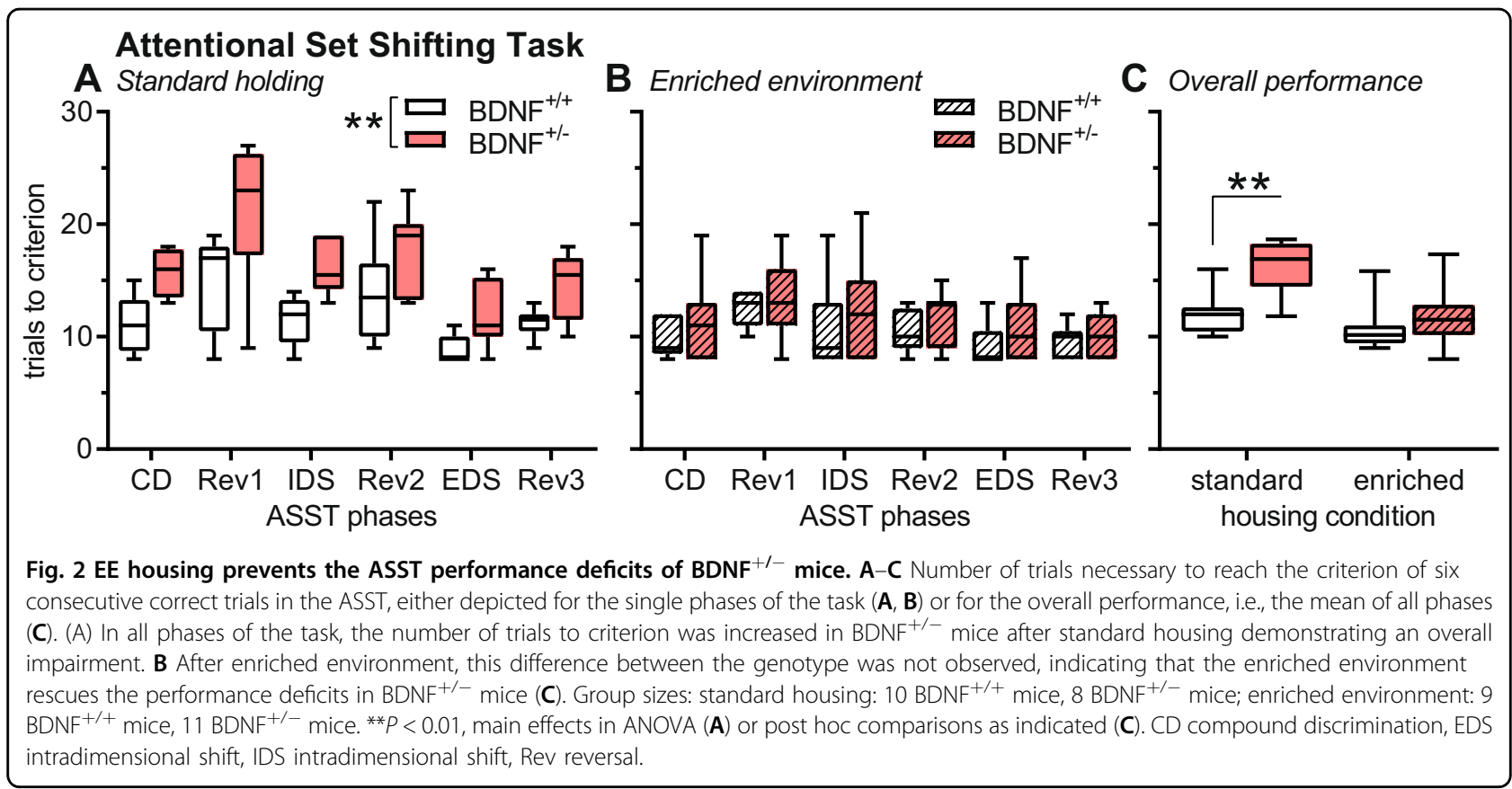

\section{Brain dissections and BDNF measurements}

Two weeks after the final behavioral experiment, the mice were anesthetized with isoflurane and euthanized by decapitation. The brains were removed and the prefrontal cortex, the dorsal hippocampus, the amygdala, and the nucleus accumbens were dissected, immediately deepfrozen, and stored at $-80{ }^{\circ} \mathrm{C}$ until further analysis. For BDNF protein quantification, we used the Quantikine BDNF-ELISA kit (R\&D Systems, Wiesbaden, Germany).

\section{Descriptive and analytical statistics}

Group sizes were chosen based on power analyses using data from previous experiments or from literature. For statistics, GraphPad Prism 8.4 (San Diego, USA) was used. Normal distribution of the data was confirmed with D'Agostino \& Pearson test and the equality of variances was checked with the Brown-Forsythe tests. Data are shown as box-and-whisker plots (box: median and quartiles, Tukey's whisker). Statistical analysis was performed with multifactorial ANOVAs followed by Holm-Sidak's multiple comparisons.

\section{Results}

\section{Impaired performance of $\mathrm{BDNF}^{+/-}$mice in the ASST is rescued by $\mathrm{EE}$}

In Fig. 2, the mean number of trials to reach the criterion of six consecutive successful trials is depicted. After standard housing, $\mathrm{BDNF}^{+/-}$mice needed more trials to complete the different ASST phases than $\mathrm{BDNF}^{+/+}$mice
$\left(F_{1,16}=20.23, P=0.0004\right.$, Fig. $\left.2 \mathrm{~A}\right)$. There was also a significant effect of the ASST phases $\left(F_{5,80}=12.60, P<\right.$ $0.0004)$ but no genotype $\times$ phase interaction $\left(F_{5,80}=0.59\right.$, $P=0.71)$. This indicates an overall, i.e., not phase-specific, deficit of standard-housed $\mathrm{BDNF}^{+/-}$mice in the ASST.

After EE, the mice's performance was not affected by the genotype $\left(F_{1,18}=1.08, P=0.31\right.$, Fig. $\left.2 \mathrm{~B}\right)$. Again, the performance was different in the different ASST phases $\left(F_{5,90}=31.80, P=0.0008\right)$ and there was no phase $\mathrm{x}$ genotype interaction $\left(F_{5,90}=1.62, P=0.95\right)$. In addition, we analyzed the overall performance (Fig. $2 \mathrm{C}$ ). This analysis revealed significant effects of genotype $\left(F_{1,34}=14.38, P=\right.$ $0.0006)$ and housing condition $\left(F_{1,34}=16.68, P=0.0003\right)$, as well as a genotype $\mathrm{x}$ housing condition interaction $\left(F_{1,34}=5.20, P=0.03\right)$. Post hoc comparisons showed a significantly impaired overall performance in $\mathrm{BDNF}^{+/-}$ mice after standard housing $(t=4.18, P=0.004)$ but not after EE housing $(t=1.10, P=0.28)$. Of note, while overall ASST performance in $\mathrm{BDNF}^{+/+}$mice was not affected by EE housing, performance in the reversal phases was improved by $\operatorname{EE}(t=2.17, P=0.045$, see Supplementary Fig. 2).

These effects were fully supported by the analyses of the number of errors (see Supplementary Fig. 3). Taken together, ASST performance was impaired in $\mathrm{BDNF}^{+/-}$ mice, and this impairment was rescued by EE housing. Of note, neither the genotype nor enriched environment affected the body weight of the mice in this experiment (see Supplementary Fig. 4). 


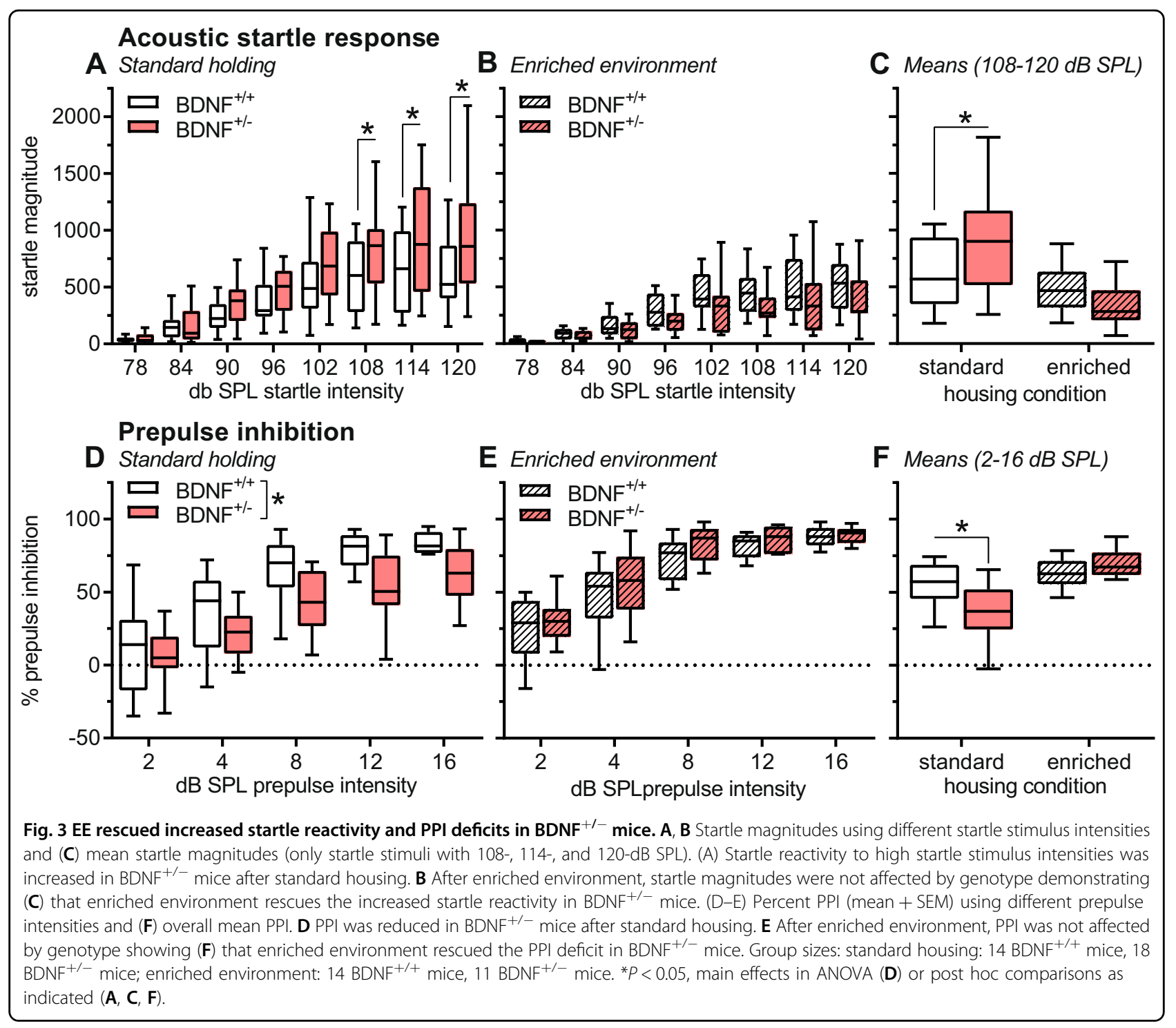

\section{Increased startle reactivity in $\mathrm{BDNF}^{+/-}$mice is rescued} by $\mathrm{EE}$

We measured the startle magnitudes to acoustic stimuli with different intensities. Standard-housed $\mathrm{BDNF}^{+/-}$ mice had an exaggerated startle response at higher startle stimulus intensities compared to their $\mathrm{BDNF}^{+/+}$littermates (Fig. 3A, interaction genotype $x$ stimulus intensity: $\left.F_{7,210}=2.14, P=0.04\right)$. There was no main effect of genotype $\left(F_{1,30}=2.81, P=0.10\right)$ but of stimulus intensity $\left(F_{7,210}=37.73, P<0.0001\right)$. Post hoc comparisons showed higher startle magnitudes in $\mathrm{BDNF}^{+/-}$mice at stimulus intensities of 108-120-dB SPL ( $\left.t^{\prime} \mathrm{s}>2.24, P^{\prime} \mathrm{s}<0.03\right)$.

These differences were not observed if mice were EEhoused (Fig. 3B). Again, stimulus intensity had the main effect $\left(F_{7,175}=44.11, P<0.0001\right)$ but there was neither a genotype effect $\left(F_{1,25}=2.45, P=0.13\right)$ nor an interaction $\left(F_{7,175}=0.98, P=0.45\right)$. This beneficial effect of $E E$ was fully supported by an analysis including the data of both housing conditions (Fig. 3C). EE rescued the exaggerated startle response of $\mathrm{BDNF}^{+/-}$mice observed in standard housing (interaction genotype $\mathrm{x}$ housing condition: $F_{1,55}$ $=4.39, P=0.04)$. In addition, EE decreased overall startle magnitudes, irrespective of genotype $\left(F_{1,55}=10.36, P=\right.$ $0.002)$, whereas there was no main effect of the factor genotype $\left(F_{1,55}=1.02, P=0.32\right)$.

\section{PPI deficits in $\mathrm{BDNF}^{+/-}$mice are rescued by $\mathrm{EE}$}

In this test, the startle magnitudes to startle stimuli, preceded by prepulses with different intensities, were measured. With standard housing, PPI was impaired in $\mathrm{BDNF}^{+/-}$mice (Fig. 3D). There were main effects of prepulse intensity $\left(F_{4,112}=83.75, P<0.0001\right)$ and genotype $\left(F_{1,28}=6.04, P=0.02\right)$ but no interaction between these two factors $\left(F_{4,112}=1.01, P=0.40\right)$. 


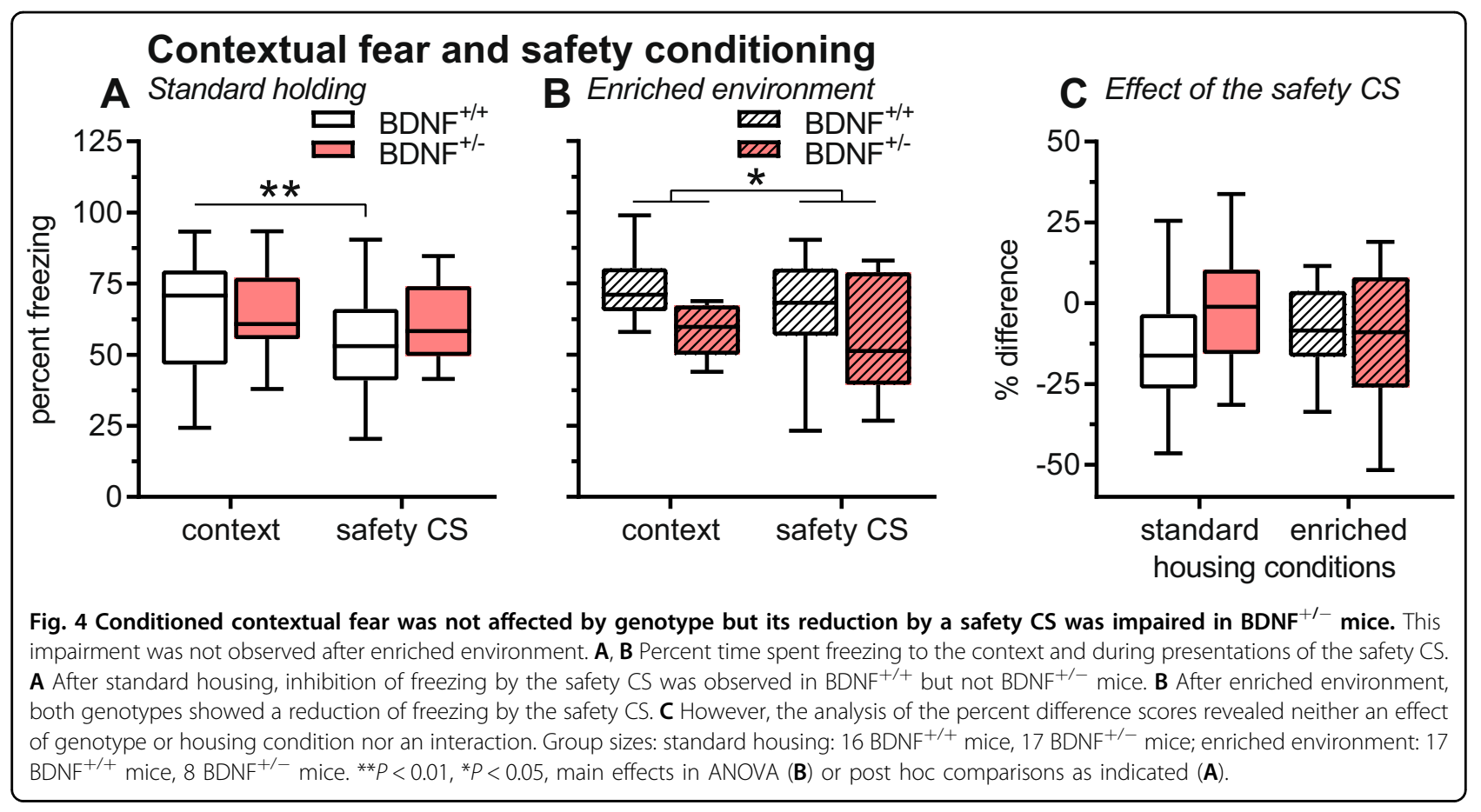

With EE, genotype did not affect PPI $\left(F_{1,23}=1.01, P=\right.$ 0.32 , Fig. 3E). Statistical analysis still showed an effect of prepulse intensity $\left(F_{4,92}=122.30, P<0.0001\right)$, however, there was no interaction between these two factors $\left(F_{4,92}\right.$ $=0.50, P=0.74)$. An additional analysis with data from both housing conditions (Fig. 3F) revealed that EE prevented the PPI deficit in $\mathrm{BDNF}^{+/-}$mice observed after standard housing (interaction genotype $\mathrm{x}$ housing condition: $\left.F_{1,51}=5.91, P=0.02\right)$. EE generally increased PPI $\left(F_{1,51}=15.94, P=0.002\right)$, whereas the genotype did not have main effects $\left(F_{1,51}=1.01, P=0.30\right)$.

Impaired safety learning in $\mathrm{BDNF}^{+/-}$mice is rescued by $\mathrm{EE}$

After safety conditioning, the mice were tested for their fear response to the conditioning boxes and their response to the safety CS. After standard housing, both genotypes expressed similar levels of freezing to the conditioning context (Fig. $4 \mathrm{~A}, F_{1,31}=0.59, P=0.45$ ) demonstrating successful contextual fear conditioning in both genotypes. During the safety CS, this freezing response was reduced in $\mathrm{BDNF}^{+/+}$but not in the $\mathrm{BDNF}^{+/-}$ mice (interaction: $F_{1,31}=4.07, P=0.05$; safety CS: $F_{1,31}=$ $11.74, P=0.002$ ) indicating impaired safety learning in $\mathrm{BDNF}^{+/-}$mice. This was different after EE housing (Fig. $4 \mathrm{~B})$. There was a main effect of the safety CS $\left(F_{1,23}=6.76\right.$, $P=0.02)$ but neither genotype effects $\left(F_{1,23}=2.50, P=\right.$ $0.13)$ nor an interaction between these factors $\left(F_{1,23}=0.10, P=0.76\right)$. This suggests that EE rescued the impaired safety learning observed in $\mathrm{BDNF}^{+/-}$mice after standard housing. For additional analysis, we calculated the percent freezing reduction by the safety CS (Fig. 4C): there were no effects of genotype and housing condition (F's $<0.62, P^{\prime}$ s $>0.61$ ) and the interaction did not reach the level of significance $\left(F_{1,54}=2.49, P=0.12\right)$.

\section{BDNF brain levels}

Two weeks after the behavioral experiments, the mice were euthanized, the brains were dissected, and the BDNF levels in different brain areas were measured.

In standard-housed $\mathrm{BDNF}^{+/+}$mice, the total $\mathrm{BDNF}$ levels differed between regions with values of ca. 15-20 pg $\mathrm{BDNF} / \mathrm{mg}$ brain tissue in the amygdala and the dorsal hippocampus and levels of ca. 5-10 pg BDNF/mg brain tissue in the nucleus accumbens and the prefrontal cortex (Fig. 5A-D). However, the effects of genotype and housing conditions were the same in all brain regions. BDNF levels were reduced in $\mathrm{BDNF}^{+/-}$mice $(F \mathrm{~s}=28.99$, $\left.P^{\prime} \mathrm{S}<0.0001\right)$ and EE housing increased BDNF levels $\left(F \mathrm{~s}=63.25, P^{\prime} \mathrm{s}<0.0001\right)$. For the amygdala and the dorsal hippocampus, the increase in BDNF levels after enriched environment was more pronounced in the wildtype mice (F's $>8.17, P^{\prime} \mathrm{s}<0.007$ ), whereas no interaction between genotype and enriched environment effect was observed in the nucleus accumbens and the prefrontal cortex $\left(F^{\prime} \mathrm{s}<2.65, P^{\prime} \mathrm{s}>0.11\right)$.

We analyzed whether individual BDNF levels in different brain areas were correlated with individual performance in the different tests. We generally found that sigmoid regression curves best fitted the results. This means that from a particular BDNF level on, no further 


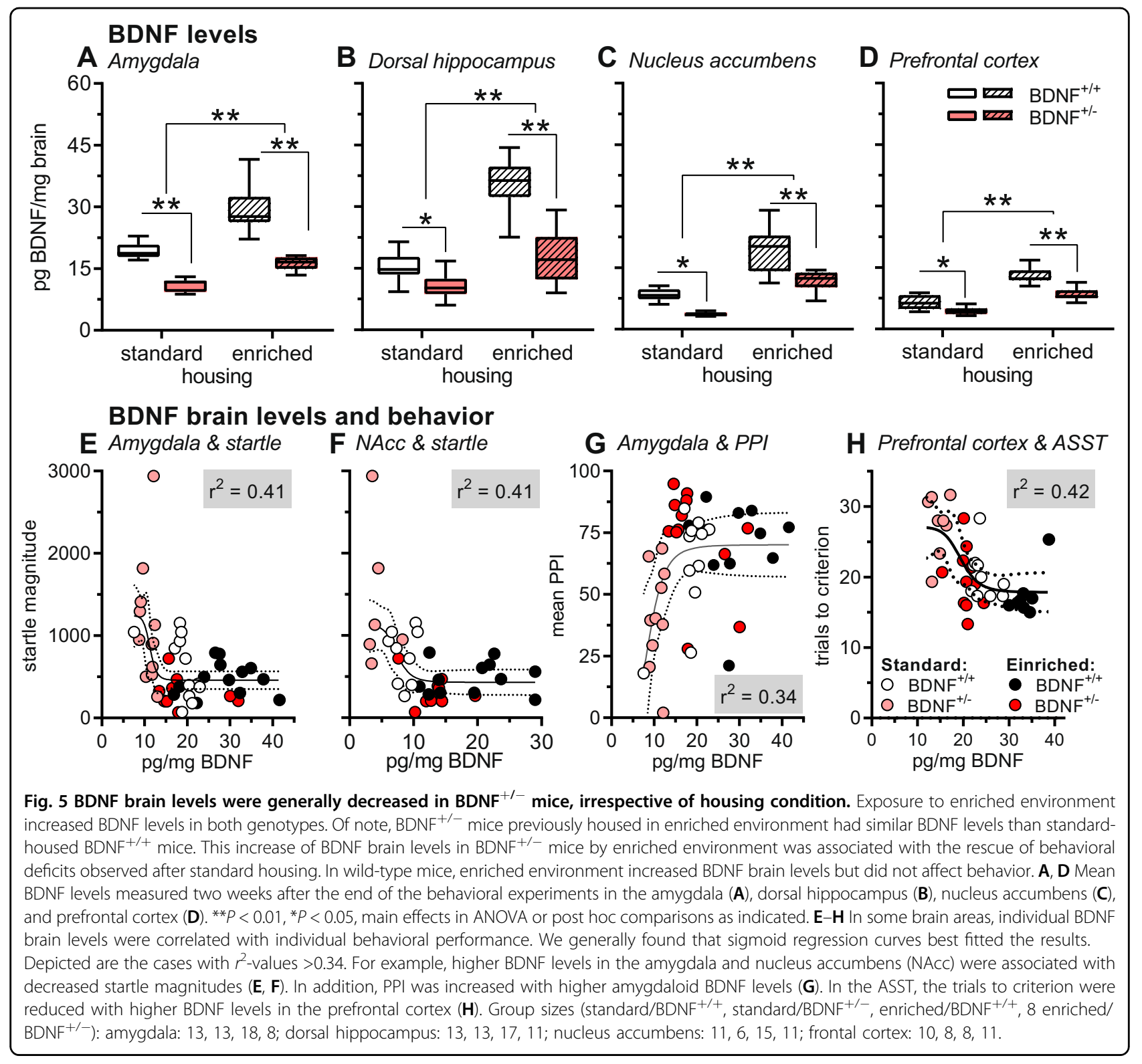

behavioral changes were observed. In Fig. 5E-H, the brain areas with the best $r^{2}$ values are depicted. These analyses showed that BDNF levels in the amygdala and nucleus accumbens were best correlated with the startle magnitude $\left(r^{2}\right.$ values $>0.41$, Fig. 5E, F). In addition, the startle magnitudes were well correlated with BDNF levels in the prefrontal cortex $\left(r^{2}=0.38\right)$, while there was only a moderate correlation with BDNF levels in the dorsal hippocampus $\left(r^{2}=0.20\right.$, data not shown). For PPI, we found that BDNF levels in the amygdala correlated best with behavioral performance $\left(r^{2}=0.34\right.$, Fig. 5G), while BDNF levels in the prefrontal cortex and nucleus accumbens were only moderately correlated with PPI $\left(r^{2}\right.$ $=0.27$ and 0.21 , respectively, data not shown). There was no correlation between PPI and hippocampal BDNF levels $\left(r^{2}=0.05\right.$, data not shown). Furthermore, we observed only very poor correlations of BDNF levels with safety learning (amygdala: $r^{2}=0.03$; nucleus accumbens: $r^{2}=0.13$; dorsal hippocampus: $r^{2}=0.04$; prefrontal cortex: $r^{2}=0.19$, data not shown). Last, we found that BDNF levels in the prefrontal cortex were well correlated with overall performance in the ASST $\left(r^{2}=0.42\right.$, Fig. $\left.5 \mathrm{H}\right)$.

\section{Discussion}

Increasing evidence led to the hypothesis that the neurotrophin BDNF is involved in behavioral endophenotypes of schizophrenia ${ }^{23-25,28-31,37}$. The aim of the present study was to support and better understand this hypothesis utilizing $\mathrm{BDNF}^{+/-}$mice. To this end, male mature adult $\mathrm{BDNF}^{+/-}$mice were submitted to several 
behavioral tests relevant for schizophrenia to investigate whether genetically decreased BDNF levels lead to schizophrenia-typical behavioral impairments. After standard housing, we observed impaired cognitive performance in the ASST, exaggerated startle magnitudes, and PPI deficits, as well as impaired safety learning in $\mathrm{BDNF}^{+/-}$mice. All these changes were rescued by EE housing of the mice. Analyses of the brain BDNF levels confirmed that $\mathrm{BDNF}^{+/-}$mice have $30-60 \%$ less $\mathrm{BDNF}$ than their $\mathrm{BDNF}^{+/+}$littermates. $\mathrm{EE}$ increased BDNF brain levels in both genotypes by $60-200 \%$. This EE-induced recovery of BDNF levels in $\mathrm{BDNF}^{+/-}$mice back to levels present in standard-housed $\mathrm{BDNF}^{+/+}$animals suggests that the rescue of the behavioral impairments was based on the restoration of BDNF brain levels.

In contrast to many previous behavioral studies in $\mathrm{BDNF}^{+/-}$mice, mature adults (5-6 months) instead of young adults' (2-3 months) $\mathrm{BDNF}^{+/-}$mice were used here. This was based on previous data showing that particular behavioral impairments in $\mathrm{BDNF}^{+/-}$mice are not present in young adults but in mature adult $\mathrm{BDNF}^{+/-}$ mice ${ }^{51-53}$. A second rationale for the use of this age was that the first admission for schizophrenia is usually during mature adultness ${ }^{28,29,57}$. At mature adultness and after standard housing, this study found several pronounced behavioral impairments in male $\mathrm{BDNF}^{+/-}$mice.

First, $\mathrm{BDNF}^{+/-}$mice had deficits in the ASST. This task consists of several phases and starts with discrimination learning followed by several phases demanding cognitive flexibility, i.e., reversals and intra- and extradimensional shifts $^{42,80}$. Using a similar behavioral paradigm in an operant chamber, impaired reversal learning was found previously in $\mathrm{BDNF}^{+/-}$mice ${ }^{50}$. In the present study, $\mathrm{BDNF}^{+/-}$mice had performance deficits throughout all phases of the ASST, i.e., the deficit was not restricted to reversal learning but also present in the other phases. Of note, such a general ASST performance deficit has been often observed in schizophrenic patients ${ }^{81-83}$. Our finding further supports human data showing that disruption of BDNF functioning leads to impaired cognitive flexibility $^{84,85}$. Based on reports showing that interventions supporting BDNF function can facilitate and/or restore cognitive flexibility ${ }^{86,87}$, we housed our mice in EE that is known to increase BDNF brain levels ${ }^{88}$. We observed both expected EE effects: increased brain BDNF levels, as well as a rescue of the impairment in cognitive flexibility. To the best of our knowledge, such a complete rescue of a BDNF heterozygosity-induced deficit in cognitive flexibility by noninvasive restoration of BDNF brain levels back to normal through EE, has not been described before. However, Chourbaji et al. reported previously that $\mathrm{EE}$ can rescue behavioral changes of $\mathrm{BDNF}^{+-}$mice in anxiety, object recognition, and pain sensitivity ${ }^{58}$. These and the present findings raise the interesting possibility that the right dosage of EE might ameliorate BDNFdependent deficits in other neuropsychiatric and neurological disorders.

Our second experiment was focused on startle reactivity. In humans, disrupted BDNF functioning leads to a decrease of the startle response ${ }^{89}$ and for schizophrenia patients, no changes in startle reactivity are described ${ }^{90}$. Here, we observed an increased startle reactivity in $\mathrm{BDNF}^{+/-}$mice when intense startle stimuli were used. This is in line with previous studies showing an exaggerated startle response in $\mathrm{BDNF}^{+/-}$mice ${ }^{91,92}$. It is known that BDNF plays an important role in inner ear development ${ }^{93}$ and that age-related hearing loss is accompanied by a reduction of BDNF in cochlear neurons ${ }^{94}$. Of note, the higher reactivity of $\mathrm{BDNF}^{+/-}$mice to intense startle stimuli was prevented by EE housing. Importantly, these changes in startle reactivity were not caused by differences in body weight, since in this study body weight was neither affected by genotype nor by housing condition. An increased body weight in $\mathrm{BDNF}^{+/-}$ mice was repeatedly reported ${ }^{58,69,95,96}$, including previous studies of our group ${ }^{51}$. However, we observed in our breeding line that this body weight difference disappeared with repeated backcrossing to $\mathrm{C} 57 \mathrm{Bl} / 6 \mathrm{~J}^{53}$.

More related to schizophrenia is the PPI deficit we observed in the $\mathrm{BDNF}^{+/-}$mice, which is in line with recently published data ${ }^{91}$. PPI is an operational measure of sensorimotor gating that is deficient in schizophrenia $^{97,98}$. However, polymorphisms interfering with BDNF secretion appear to be not sufficient to impair sensorimotor gating in humans ${ }^{99}$. Previously, no consistent effects of BDNF deficiency on PPI and pharmacologically induced PPI deficits were found in mice and rats ${ }^{49,91,100,101}$. In some studies, male $\mathrm{BDNF}^{+/-}$mice were found to be more or less sensitive to treatments impairing $\mathrm{PPI}^{49,92,101}$. An explanation for these inconsistent effects on PPI could be the different ages of the mice during testing. In mature adult $\mathrm{BDNF}^{+/-}$mice, we found robust PPI deficits in this study. Despite it was shown that central BDNF administration can rescue PPI deficits ${ }^{102}$ and that EE can increase BDNF levels ${ }^{88}$ and rescue other behavioral deficits in $\mathrm{BDNF}^{+/-}$mice ${ }^{58,103}$, it was not tested so far whether PPI-related changes in $\mathrm{BDNF}^{+/-}$mice can be rescued by EE. In the present study, we found no PPI deficit in $\mathrm{BDNF}^{+/-}$mice anymore, if they were exposed for two months to EE.

Last, we also tested our animals on learned safety and learned contextual fear. Contextual fear was not affected in $\mathrm{BDNF}^{+/-}$mice. This is in line with published findings ${ }^{104}$ while others described deficits ${ }^{64}$. Of note, we used a protocol with many US presentations that might rescue deficits observed with weaker conditioning protocols. Interestingly, learned safety, i.e., fear inhibition, was impaired in $\mathrm{BDNF}^{+/-}$mice. However, it is important to 
note that safety learning was generally not very pronounced in the present study. Nevertheless, the observed safety learning deficit is in line with the one described in patients with schizophrenia ${ }^{47,48}$ and psychosis ${ }^{105}$. Again, EE housing rescued the observed deficit in our mice.

After completing the behavioral tests, we measured BDNF protein levels in different brain areas. It should be noted that the used ELISA for BDNF measurement has a limited cross-reactivity with pro-BDNF (ca. 13\%), i.e., the measured levels are not exclusively mature BDNF. However, we generally observed that both experimental factors of the present study robustly affected BDNF levels: BDNF haploinsufficiency decreased and EE housing increased BDNF levels in all analyzed brain areas ${ }^{38,88}$. In some of the brain areas, the BDNF levels were well correlated with behavioral performance. In general, increased BDNF levels were associated with a rescue of the behavioral deficits in $\mathrm{BDNF}^{+/-}$mice. However, the BDNF increase in $\mathrm{BDNF}^{+/+}$mice did not affect behavioral performance, disregarding the mild improvement in reversal learning. This suggests that a certain threshold level of BDNF, which needs to be well above the $50 \%$ reduction found in $\mathrm{BDNF}^{+/-}$animals, is required for intact functioning of the brain, while an additional increase of BDNF levels beyond this threshold does not further improve brain functioning $^{51,106}$. However, this does not exclude that higher BDNF levels have protective effects on the future, e.g., age-related impairments ${ }^{107}$. Of note, too high, i.e., exaggerated BDNF levels, e.g., in BDNF-overexpressing mice, are also associated with behavioral impairments, including working memory deficits, PPI deficits, decreased startle, and increased anxiety ${ }^{108}$.

We observed correlations between BDNF brain levels and behavior here. Of note, such correlations do not necessarily indicate causality. However, it is not simple to experimentally prove that the mechanism of action for the rescue of behavioral deficits by enriched environment is the increase of BDNF brain levels. Potential experiments would be to "replace" enriched environment by chronic pharmacological activation of $\operatorname{TrkB}$ receptors. Such experiments have been performed in previous studies using either a TrkB receptor-activating antibody or the TrkB receptor agonist 7,8-dihydroxyflavone, and both manipulations were able to rescue memory deficits in different rodent models of human diseases such as schizophrenia $^{109,110}$, depression ${ }^{111}$, Down syndrome ${ }^{112,113}$, Parkinson's disease ${ }^{114}$, Hungtington's disease ${ }^{115}$, and Alzheimer's disease ${ }^{116-119}$ (but see also ${ }^{120}$ ). Another possibility would be to block the enriched environment effect by chronic application of a BDNF scavenger (e.g., TrkB-Fc). However, since the temporal and brain-wide spatial pattern of the enriched environment effect is not known yet, it is presently unclear whether such pharmacological interventions should use the chronic, subchronic, or acute application, and whether systemic vs. local, or continuous vs. intermittent regimes for activation of BDNF/TrkB signaling should be used. Future studies need to focus on a better understanding of the exact patterns of the enriched environment effects, which would then be a good basis for follow-up studies with the aforementioned pharmacological interventions.

In summary, we showed that BDNF haploinsufficiency in mature adult mice is associated with different behavioral endophenotypes of schizophrenia and that these endophenotypes are rescued by EE housing. However, our study has several limitations: first, we only tested male mature adult mice. Therefore, it is unclear whether the observed endophenotypes developed in a schizophreniatypical way, i.e., after puberty, and whether the same can be observed in female mice. We focused on male mice since in some human studies a more important role of BDNF in schizophrenia was found in male patients ${ }^{33,121}$. Of note, many of the behavioral and neurochemical changes described in $\mathrm{BDNF}^{+/-}$mice were only observed or more pronounced in male mice ${ }^{49,101,122,123}$. Second, we showed that EE housing increased BDNF brain levels and rescued the observed endophenotypes. However, despite it is very unlikely, these two effects of $\mathrm{EE}$ do not have to be associated with each other. It could be that the observed rescue was not mediated by the increase in BDNF levels, but another mechanism that is also influenced by EE (e.g., orexin $A^{124,125}$ ). Third, it is unclear which aspect of $E E$ was responsible for the rescue of behavioral deficits and the increase in BDNF levels, respectively. We suggest that wheel running during EE housing, i.e., voluntary exercise, plays a major role in increasing BDNF levels and rescuing the behavioral phenotypes. This is in line with numerous reports showing that physical exercise efficiently reduces psychiatric symptoms in schizophrenia and other neuropsychiatric disorders ${ }^{126,127}$.

\section{Acknowledgements \\ This study was supported by the German Science Foundation (SFB 779 projects B06 and B13) and by the JPND project CIRCPROT (project no. 643417) jointly supported by BMBF and Horizon 2020 co-funding. The funding institutions had no influence on data acquisition, analysis, or decision to publish the results. \\ Author details \\ ${ }^{1}$ Institute for Pharmacology and Toxicology, Otto-von-Guericke University Magdeburg, Magdeburg, Germany. ${ }^{2}$ Institute of Physiology, Otto-von-Guericke University Magdeburg, Magdeburg, Germany. ${ }^{3}$ Center for Behavioral Brain Sciences, Otto-von-Guericke University Magdeburg, Magdeburg, Germany}

\section{Author contributions}

M.H., J.J., and A.D. planned experiments, collected, and analyzed the data; A.D. T.E., V.L., and M.F. designed the study, interpreted the results; T.E., V.L., and M.F. wrote the paper. All authors contributed to critically revising this work and approving a final version.

Funding

Open Access funding enabled and organized by Projekt DEAL. 


\section{Conflict of interest}

The authors declare no competing interests.

\section{Publisher's note}

Springer Nature remains neutral with regard to jurisdictional claims in published maps and institutional affiliations.

Supplementary information The online version contains supplementary material available at https://doi.org/10.1038/s41398-021-01365-z.

Received: 10 December 2020 Revised: 26 March 2021 Accepted: 12 April 2021

Published online: 22 April 2021

\section{References}

1. van Os, J. \& Kapur, S. Schizophrenia. Lancet 374, 635-645 (2009).

2. Lewis, D. A. \& Levitt, P. Schizophrenia as a disorder of neurodevelopment. Annu. Rev. Neurosci. 25, 409-432 (2002).

3. Altamura, A. C., Pozzoli, S., Fiorentini, A. \& Dell'Osso, B. Neurodevelopment and inflammatory patterns in schizophrenia in relation to pathophysiology. Prog. Neuropsychopharmacol. Biol. Psychiatry 42, 63-70 (2013).

4. Monji, A. et al. Neuroinflammation in schizophrenia especially focused on the role of microglia. Prog. Neuropsychopharmacol. Biol. Psychiatry 42, 115-121 (2013).

5. Sawa, A. \& Snyder, S. H. Schizophrenia: diverse approaches to a complex disease. Science 296, 692-695 (2002).

6. Park, H. \& Poo, M. M. Neurotrophin regulation of neural circuit development and function. Nat. Rev. Neurosci. 14, 7-23 (2013).

7. Brigadski, B. \& Lessmann, V. BDNF: Ein Regulator von Lern- und Gedächtnisprozessen mit klinischem Potenzial. Neuroreport 20, 166-177 (2014).

8. Leßmann, V. \& Brigadski, T. Mechanisms, locations, and kinetics of synaptic BDNF secretion: an update. Neurosci. Res. 65, 11-22 (2009).

9. Zagrebelsky, M. \& Korte, M. Form follows function: BDNF and its involvement in sculpting the function and structure of synapses. Neuropharmacology $\mathbf{7 6}$, 628-638 (2014).

10. Edelmann, E., Leßmann, V. \& Brigadski, T. Pre- and postsynaptic twists in BDNF secretion and action in synaptic plasticity. Neuropharmacology $\mathbf{7 6}$, 610-627 (2014).

11. Tyler, W. J., Alonso, M., Bramham, C. R. \& Pozzo-Miller, L. D. From acquisition to consolidation: on the role of brain-derived neurotrophic factor signaling in hippocampal-dependent learning. Learn. Mem. 9, 224-237 (2002).

12. Heldt, S. A., Stanek, L., Chhatwal, J. P. \& Ressler, K. J. Hippocampus-specific deletion of BDNF in adult mice impairs spatial memory and extinction of aversive memories. Mol. Psychiatry 12, 656-670 (2007).

13. Blurton-Jones, M. et al. Neural stem cells improve cognition via BDNF in a transgenic model of Alzheimer disease. Proc. Natl Acad. Sci. USA 106, 13594-13599 (2009).

14. Mizuno, M., Yamada, K., Olariu, A., Nawa, H. \& Nabeshima, T. Involvement of brain-derived neurotrophic factor in spatial memory formation and maintenance in a radial arm maze test in rats. J. Neurosci. 20, 7116-7121 (2000).

15. Rattiner, L. M., Davis, M., French, C. T. \& Ressler, K. J. Brain-derived neurotrophic factor and tyrosine kinase receptor $B$ involvement in amygdaladependent fear conditioning. J. Neurosci. 24, 4796-4806 (2004).

16. Egan, M. F. et al. The BDNF val66met polymorphism affects activitydependent secretion of BDNF and human memory and hippocampal function. Cell 112, 257-269 (2003).

17. Autry, A. E. \& Monteggia, L. M. Brain-derived neurotrophic factor and neuropsychiatric disorders. Pharmacol. Rev. 64, 238-258 (2012).

18. Duman, R. S., Deyama, S. \& Fogaça, M. V. Role of BDNF in the pathophysiology and treatment of depression: Activity-dependent effects distinguish rapid-acting antidepressants. Eur. J. Neurosci. 53, 126-139 (2021).

19. Lindholm, J. S. O. \& Castrén, E. Mice with altered BDNF signaling as models for mood disorders and antidepressant effects. Front. Behav. Neurosci. 8, 143-143 (2014).

20. Lu, B., Nagappan, G. \& Lu, Y. BDNF and synaptic plasticity, cognitive function, and dysfunction. Handb. Exp. Pharm. 220, 223-250 (2014).
21. Meis, S., Endres, T. \& Lessmann, V. Neurotrophin signalling in amygdaladependent cued fear learning. Cell Tissue Res 382, 161-172 (2020).

22. Jordan, W. et al. Oxidative stress in drug-naïve first episode patients with schizophrenia and major depression: effects of disease acuity and potential confounders. Eur. Arch. Psychiatry Clin. Neurosci. 268, 129-143 (2018).

23. Pillai, A. et al. Decreased BDNF levels in CSF of drug-naive first-episode psychotic subjects: correlation with plasma BDNF and psychopathology. Int. J. Neuropsychopharmacol. 13, 535-539 (2010).

24. Thompson Ray, M., Weickert, C. S., Wyatt, E. \& Webster, M. J. Decreased BDNF, trkB-TK+ and GAD(67) mRNA expression in the hippocampus of individuals with schizophrenia and mood disorders. J. Psychiatry Neurosci. 36, 195-203 (2011).

25. Weickert, C. S. et al. Reduced brain-derived neurotrophic factor in prefrontal cortex of patients with schizophrenia. Mol. Psychiatry 8, 592-610 (2003).

26. Yang, B., Ren, Q., Zhang, J. C., Chen, Q. X. \& Hashimoto, K. Altered expression of BDNF, BDNF pro-peptide and their precursor proBDNF in brain and liver tissues from psychiatric disorders: rethinking the brain-liver axis. Transl. Psychiatry 7, e1128 (2017).

27. Takahashi, M. et al. Abnormal expression of brain-derived neurotrophic factor and its receptor in the corticolimbic system of schizophrenic patients. Mol. Psychiatry 5, 293-300 (2000).

28. Buckley, P. F., Pillai, A., Evans, D., Stirewalt, E. \& Mahadik, S. Brain derived neurotropic factor in first-episode psychosis. Schizophrenia Res. 91, 1-5 (2007).

29. Chen, D. C. et al. Decreased levels of serum brain-derived neurotrophic factor in drug-naive first-episode schizophrenia: relationship to clinical phenotypes. Psychopharmacology 207, 375-380 (2009).

30. Notaras, M., Hill, R. \& van den Buuse, M. A role for the BDNF gene Val66Met polymorphism in schizophrenia? A comprehensive review. Neurosci. Biobehav. Rev. 51, 15-30 (2015).

31. Gratacòs, M. et al. Brain-derived neurotrophic factor Val66Met and psychiatric disorders: meta-analysis of case-control studies confirm association to substance-related disorders, eating disorders, and schizophrenia. Biol. Psychiatry 61, 911-922 (2007).

32. Spalletta, G. et al. BDNF Val66Met polymorphism is associated with aggressive behavior in schizophrenia. Eur. Psychiatry 25, 311-313 (2010).

33. Lu, W. et al. Association between BDNF Val66Met polymorphism and cognitive performance in antipsychotic-naive patients with schizophrenia. J. Mol. Neurosci. 47, 505-510 (2012).

34. Numata, S. et al. Brain-derived neurotrophic factor (BDNF) Val66Met polymorphism in schizophrenia is associated with age at onset and symptoms. Neurosci. Lett. 401, 1-5 (2006)

35. Kheirollahi, M., Kazemi, E. \& Ashouri, S. Brain-derived neurotrophic factor gene Val66Met polymorphism and risk of schizophrenia: a meta-analysis of casecontrol studies. Cell Mol. Neurobiol. 36, 1-10 (2016).

36. Zhao, X. et al. The brain-derived neurotrophic factor Val66-Met polymorphism is not associated with schizophrenia: an updated meta-analysis of 11,480 schizophrenia cases and 13,490 controls. Psychiatry Res. 225, 217 (2015).

37. Favalli, G., Li, J., Belmonte-de-Abreu, P., Wong, A. H. C. \& Daskalakis, Z. J. The role of BDNF in the pathophysiology and treatment of schizophrenia. J. Psychiatr. Res. 46, 1-11 (2012).

38. Korte, M. et al. Hippocampal long-term potentiation is impaired in mice lacking brain-derived neurotrophic factor. Proc. Natl Acad. Sci. USA 92, 8856-8860 (1995).

39. Allen, A. J., Griss, M. E., Folley, B. S., Hawkins, K. A. \& Pearlson, G. D. Endophenotypes in schizophrenia: a selective review. Schizophrenia Res. 109, 24-37 (2009).

40. Fendt, M. \& Koch, M. Translational value of startle modulations. Cell Tiss. Res. 354, 287-295 (2013).

41. Geyer, M. A., Krebs-Thomson, K., Braff, D. L. \& Swerdlow, N. R. Pharmacological studies of prepulse inhibition models of sensorimotor gating deficits in schizophrenia: a decade in review. Psychopharmacology 156, 117-154 (2001).

42. Bissonette, G. B. \& Powell, E. M. Reversal learning and attentional set-shifting in mice. Neuropharmacology 62, 1168-1174 (2012).

43. Pollak, D. D., Monje, F. J. \& Lubec, G. The learned safety paradigm as a mouse model for neuropsychiatric research. Nat. Protoc. 5, 954-962 (2010).

44. Khalil, R. \& Fendt, M. Increased anxiety but normal fear and safety learning in orexin-deficient mice. Behav. Brain Res. 320, 210-218 (2017).

45. Martins Serra, A., Jones, S. H., Toone, B. \& Gray, J. A. Impaired associative learning in chronic schizophrenics and their first-degree relatives: A study of 
latent inhibition and the Kamin blocking effect. Schizophrenia Res. 48, 273-289 (2001).

46. Escobar, M., Oberling, P. \& Miller, R. R. Associative deficit accounts of disrupted latent inhibition and blocking in schizophrenia. Neurosci. Biobehav. Rev. 26, 203-216 (2002).

47. Holt, D. J. et al. Extinction memory is impaired in schizophrenia. Biol. Psychiatry 65, 455-463 (2009).

48. Holt, D. J., Coombs, G., Zeidan, M. A., Goff, D. C. \& Milad, M. R. Failure of neural responses to safety cues in schizophrenia. Arch. Gen. Psychiatry 69, 893-903 (2012).

49. Klug, M. et al. Long-term behavioral and NMDA receptor effects of youngadult corticosterone treatment in BDNF heterozygous mice. Neurobiol. Dis. 46, 722-731 (2012)

50. Parikh, V., Naughton, S. X., Yegla, B. \& Guzman, D. M. Impact of partial dopamine depletion on cognitive flexibility in BDNF heterozygous mice. Psychopharmacology 233, 1361-1375 (2016).

51. Endres, T. \& Lessmann, V. Age-dependent deficits in fear learning in heterozygous BDNF knock-out mice. Learn. Mem. 19, 561-570 (2012).

52. Psotta, L., Lessmann, V. \& Endres, T. Impaired fear extinction learning in adult heterozygous BDNF knock-out mice. Neurobiol. Learn. Mem. 103, 34-38 (2013).

53. Petzold, A., Psotta, L., Brigadski, T., Endres, T. \& Lessmann, V. Chronic BDNF deficiency leads to an age-dependent impairment in spatial learning. Neurobiol. Learn. Mem. 120, 52-60 (2015).

54. Boger, H. A. et al. Effects of brain-derived neurotrophic factor on dopaminergic function and motor behavior during aging. Genes Brain Behav. 10, 186-198 (2011).

55. Flurkey, K, Currer J. M. \& Harrison D. E. in The Mouse in Biomedical Research 2 (ed. Fox, J. G. et al.) 20 (Academic Press, 2007).

56. Jackson, S. J. et al. Does age matter? The impact of rodent age on study outcomes. Lab. Anim. 51, 160-169 (2016).

57. Häfner, H. et al. Causes and consequences of the gender difference in age at onset of schizophrenia. Schiz. Bull. 24, 99-113 (1998).

58. Chourbaji, S. et al. Nature vs. nurture: can enrichment rescue the behavioural phenotype of BDNF heterozygous mice? Behav. Brain Res. 192, 254-258 (2008)

59. Chourbaji, S. et al. The impact of environmental enrichment on sex-specific neurochemical circuitries - effects on brain-derived neurotrophic factor and the serotonergic system. Neuroscience 220, 267-276 (2012).

60. Ernfors, P., Lee, K. F. \& Jaenisch, R. Mice lacking brain-derived neurotrophic factor develop with sensory deficits. Nature 368, 147-150 (1994).

61. Jones, K. R., Fariñas, I., Backus, C. \& Reichardt, L. F. Targeted disruption of the BDNF gene perturbs brain and sensory neuron development but not motor neuron development. Cell 76, 989-999 (1994).

62. Liebl, D. J., Tessarollo, L., Palko, M. E. \& Parada, L. F. Absence of sensory neurons before target innervation in brain-derived neurotrophic factor-, neurotrophin 3-, and TrkC-deficient embryonic mice. J. Neurosci. 17, 9113-9121 (1997).

63. Montkowski, A. \& Holsboer, F. Intact spatial learning and memory in transgenic mice with reduced BDNF. Neuroreport 8, 779-782 (1997).

64. Liu, I. Y. C., Lyons, W. E., Mamounas, L. A. \& Thompson, R. F. Brain-derived neurotrophic factor plays a critical role in contextual fear conditioning. J. Neurosci. 24, 7958-7963 (2004).

65. Abidin, I. et al. Reduced presynaptic efficiency of excitatory synaptic transmission impairs LTP in the visual cortex of BDNF-heterozygous mice. Eur. J. Neurosci. 24, 3519-3531 (2006).

66. Wiechers, B. et al. A changing pattern of brain-derived neurotrophic factor expression correlates with the rearrangement of fibers during cochlear development of rats and mice. J. Neurosci. 19, 3033-3042 (1999).

67. Linnarsson, S., Björklund, A. \& Ernfors, P. Learning deficit in BDNF mutant mice. Eur. J. Neurosci. 9, 2581-2587 (1997).

68. MacQueen, G. M. et al. Performance of heterozygous brain-derived neurotrophic factor knockout mice on behavioral analogues of anxiety, nociception, and depression. Behav. Neurosci. 115, 1145-1153 (2001).

69. Kernie, S. G., Liebl, D. J. \& Parada, L. F. BDNF regulates eating behavior and locomotor activity in mice. EMBO J. 19, 1290-1300 (2000).

70. Edelmann, E. et al. Theta burst firing recruits BDNF release and signaling in postsynaptic CA1 neurons in spike-timing-dependent LTP. Neuron 64, 1041-1054 (2015).
71. Patterson, S. L. et al. Recombinant BDNF rescues deficits in basal synaptic transmission and hippocampal LTP in BDNF knockout mice. Neuron 16, 1137-1145 (1996).

72. Korte, M., Kang, H., Bonhoeffer, T. \& Schuman, E. A role for BDNF in the latephase of hippocampal long-term potentiation. Neuropharmacology 37, 553-559 (1998).

73. Meis, S., Endres, T. \& Lessmann, V. Postsynaptic BDNF signalling regulates long-term potentiation at thalamo-amygdala afferents. J. Physiol. 590, 193-208 (2012).

74. Schildt, S., Endres, T., Lessmann, V. \& Edelmann, E. Acute and chronic interference with BDNF/TrkB-signaling impair LTP selectively at mossy fiber synapses in the CA3 region of mouse hippocampus. Neuropharmacology $\mathbf{7 1}$, 247-254 (2013)

75. Meis, S., Endres, T., Munsch, T. \& Lessmann, V. The relation between longterm synaptic plasticity at glutamatergic synapses in the amygdala and fear learning in adult heterozygous BDNF-knockout mice. Cereb. Cortex 28, 1195-1208 (2018).

76. Durairaja, A. \& Fendt M. Orexin deficiency modulates cognitive flexibility in a sex-dependent manner. Genes Brain Behav. 20, e12707 (2020).

77. Coors, A. et al. Rhodiola rosea root extract has antipsychotic-like effects in rodent models of sensorimotor gating. J. Ethnopharmacol. 235, 320-328 (2019).

78. Misane, I. et al. Time-dependent involvement of the dorsal hippocampus in trace fear conditioning in mice. Hippocampus 15, 418-426 (2005).

79. Endres, T., Widmann, K. \& Fendt, M. Are rats predisposed to learn $22 \mathrm{kHz}$ calls as danger-predicting signals? Behav. Brain Res. 185, 69-75 (2007).

80. Tait, D. S., Chase, E. A. \& Brown, V. J. Attentional set-shifting in rodents: a review of behavioural methods and pharmacological results. Curr. Pharm. Des. 20, 5046-5059 (2014).

81. Pantelis, C. et al. Comparison of set-shifting ability in patients with chronic schizophrenia and frontal lobe damage. Schizophrenia Res. 37, 251-270 (1999).

82. Ceaser, A. E. et al. Set-shifting ability and schizophrenia: a marker of clinical Illness or an intermediate phenotype? Biol. Psychiatry 64, 782-788 (2008).

83. Jazbec, S. et al. Intra-dimensional/extra-dimensional set-shifting performance in schizophrenia: impact of distractors. Schizophrenia Res. 89, 339-349 (2007).

84. Gabrys, R. L., Dixon, K. \& Anisman, H. Traumatic life events in relation to cognitive flexibility: moderating role of the BDNF Val66Met gene polymorphism. Front. Behav. Neurosci. 11, 241 (2017).

85. Grant, L. K. et al. Impaired cognitive flexibility during sleep deprivation among carriers of the brain derived neurotrophic factor (BDNF) Val66Met allele. Behav. Brain Res. 338, 51-55 (2018).

86. $\mathrm{Xu}, \mathrm{H}$. et al. Effects of duloxetine treatment on cognitive flexibility and BDNF expression in the mPFC of adult male mice exposed to social stress during adolescence. Front. Mol. Neurosci. 9, 95 (2016).

87. D'Amore, D. E., Tracy, B. A. \& Parikh, V. Exogenous BDNF facilitates strategy set-shifting by modulating glutamate dynamics in the dorsal striatum. Neuropharmacology 75, 312-323 (2013).

88. Gobbo, O. L. \& O'Mara, S. M. Impact of enriched-environment housing on brain-derived neurotrophic factor and on cognitive performance after a transient global ischemia. Behav. Brain Res. 152, 231-241 (2004).

89. Armbruster, D. et al. BDNF val66met genotype shows distinct associations with the acoustic startle reflex and the cortisol stress response in young adults and children. Psychoendocrinol 66, 39-46 (2016).

90. Swerdlow, N. R. et al. Startle gating deficits in a large cohort of patients with schizophrenia-relationship to medications, symptoms, neurocognition, and level of function. Arch. Gen. Psychiatry 63, 1325-1335 (2006).

91. Lima-Ojeda, J. M. et al. Altered prepulse inhibition of the acoustic startle response in BDNF-deficient mice in a model of early postnatal hypoxia: implications for schizophrenia. Eur. Arch. Psychiatry Clin. Neurosci. 269 439-447 (2019).

92. Klug, M. \& van den Buuse M. An investigation into "two hit" effects of BDNF deficiency and young-adult cannabinoid receptor stimulation on prepulse inhibition regulation and memory in mice. Front. Behav. Neurosci. 7, 149 (2013).

93. Johnson Chacko, L. et al. Role of BDNF and neurotrophic receptors in human inner ear development. Cell Tiss. Res. 370, 347-363 (2017).

94. Rüttiger, L. et al. BDNF mRNA expression and protein localization are changed in age-related hearing loss. Neurobiol. Aging 28, 586-601 (2007).

95. Coppola, V. \& Tessarollo L. Control of hyperphagia prevents obesity in BDNF heterozygous mice. NeuroReport 15, 2665-2668 (2004). 
96. Fox, E. A., Biddinger, J. E., Jones, K. R., McAdams, J. \& Worman, A. Mechanism of hyperphagia contributing to obesity in brain-derived neurotrophic factor knockout mice. Neuroscience 229, 176-199 (2013).

97. Braff, D. L., Geyer, M. A. \& Swerdlow, N. R. Human studies of prepulse inhibition of startle: normal subjects, patient groups, and pharmacological studies. Psychopharmacology 156, 234-258 (2001)

98. Quednow, B. B. Sensorimotor gating deficits in psychiatric disorders. Z. Neuropsychol. 19, 139-163 (2008).

99. Shaikh, M. et al. Do COMT, BDNF and NRG1 polymorphisms influence P50 sensory gating in psychosis? Psychol. Med. 41, 263-276 (2011).

100. van den Buuse, M., Biel, D. \& Radscheit, K. Does genetic BDNF deficiency in rats interact with neurotransmitter control of prepulse inhibition? Implications for schizophrenia. Prog. Neuropsychopharmacol. Biol. Psychiatry $\mathbf{7 5}$ 192-198 (2017).

101. Manning, E. \& Van Den Buuse, M. BDNF deficiency and young-adult methamphetamine induce sex-specific effects on prepulse inhibition regulation. Front. Cell. Neurosci. 7, 92 (2013).

102. Naumenko, V. S., Bazovkina, D. V., Morozova, M. V. \& Popova, N. K. Effects of brain-derived and glial cell line-derived neurotrophic factors on startle response and disrupted prepulse inhibition in mice of DBA/2J inbred strain. Neurosci. Lett. 550, 115-118 (2013).

103. Novkovic, T., Mittmann, T. \& Manahan-Vaughan, D. BDNF contributes to the facilitation of hippocampal synaptic plasticity and learning enabled by environmental enrichment. Hippocampus 25, 1-15 (2015).

104. Chourbaji, S. et al. Mice with reduced brain-derived neurotrophic factor expression show decreased choline acetyltransferase activity, but regular brain monoamine levels and unaltered emotional behavior. Mol. Brain Res. 121, 28-36 (2004).

105. Quarmley, M. et al. Reduced safety processing during aversive social conditioning in psychosis and clinical risk. Neuropsychopharmacology 44, 2247-2253 (2019).

106. Korte, M. et al. Virus-mediated gene transfer into hippocampal CA1 region restores long-term potentiation in brain-derived neurotrophic factor mutant mice. Proc. Natl Acad. Sci. USA 93, 12547-12552 (1996).

107. Wang, R. \& Holsinger, R. M. D. Exercise-induced brain-derived neurotrophic factor expression: therapeutic implications for Alzheimer's dementia. Ageing Res. Rev. 48, 109-121 (2018).

108. Papaleo, F. et al. Working memory deficits, increased anxiety-like traits, and seizure susceptibility in BDNF overexpressing mice. Learn. Mem. 18, 534-544 (2011).

109. Han, M. et al. Intake of 7,8-dihydroxyflavone during juvenile and adolescent stages prevents onset of psychosis in adult offspring after maternal immune activation. Sci. Rep. 6, 36087 (2016).

110. Yang, Y. J. et al. Small-molecule TrkB agonist 7,8-dihydroxyflavone reverses cognitive and synaptic plasticity deficits in a rat model of schizophrenia. Pharm. Biochem Behav. 122, 30-36 (2014).

111. Shirayama, Y. et al. Alterations in brain-derived neurotrophic factor (BDNF) and its precursor proBDNF in the brain regions of a learned helplessness rat model and the antidepressant effects of a TrkB agonist and antagonist. Eur. Neuropsychopharmacol. 25, 2449-2458 (2015).

112. Parrini, M. et al. Aerobic exercise and a BDNF-mimetic therapy rescue learning and memory in a mouse model of Down syndrome. Sci. Rep. 7, 16825 (2017).

113. Stagni, F. et al. A flavonoid agonist of the TrkB receptor for BDNF improves hippocampal neurogenesis and hippocampus-dependent memory in the Ts65Dn mouse model of DS. Exp. Neurol. 298, 79-96 (2017).

114. Li, X. H. et al. 7,8-dihydroxyflavone ameliorates motor deficits via suppressing a-synuclein expression and oxidative stress in the MPTP-induced mouse model of Parkinson's disease. CNS Neurosci. Ther. 22, 617-624 (2016).

115. García-Díaz Barriga, G. et al. 7,8-dihydroxyflavone ameliorates cognitive and motor deficits in a Huntington's disease mouse model through specific activation of the PLCY1 pathway. Hum. Mol. Genet 26, 3144-3160 (2017).

116. Wang, S. et al. Therapeutic potential of a TrkB agonistic antibody for Alzheimer's disease. Theranostics 10, 6854-6874 (2020).

117. Castello, N. A. et al. 7,8-Dihydroxyflavone, a small molecule TrkB agonist, improves spatial memory and increases thin spine density in a mouse mode of Alzheimer disease-like neuronal loss. PLOS ONE 9, e91453 (2014).

118. Devi, L. \& Ohno, M. 7,8-dihydroxyflavone, a small-molecule TrkB agonist, reverses memory deficits and BACE1 elevation in a mouse model of Alzheimer's disease. Neuropsychopharmacology 37, 434-444 (2012).

119. Aytan, N. et al. Protective effects of 7,8-dihydroxyflavone on neuropathological and neurochemical changes in a mouse model of Alzheimer's disease. Eur. J. Pharm. 828, 9-17 (2018).

120. Zhou, W. et al. No significant effect of 7,8-dihydroxyflavone on APP processing and Alzheimer-associated phenotypes. Curr. Alzheimer Res. 12, 47-52 (2015).

121. Golimbet, V. E., Korovătseva, G. I., Abramova, L. I., Kasparov, S. V. \& Uvarova, L. G. Association between the Val66Met polymorphism of brain-derived neurotrophic factor gene and schizophrenia in Russians. Mol. Biol. 42, 599-603 (2008).

122. Hill, R. A. \& van den Buuse, M. Sex-dependent and region-specific changes in TrkB signaling in BDNF heterozygous mice. Brain Res. 1384, 51-60 (2011).

123. Manning, E. E. \& van den Buuse, M. Altered social cognition in male BDNF heterozygous mice and following chronic methamphetamine exposure. Behav. Brain Res. 305, 181-185 (2016).

124. Öz, P., Gökalp, H. K., Göver, T. \& Uzbay, T. Dose-dependent and opposite effects of orexin $\mathrm{A}$ on prepulse inhibition response in sleep-deprived and non-sleep-deprived rats. Behav. Brain Res. 346, 73-79 (2018).

125. Chieffi, S. et al. Exercise influence on hippocampal function: possible involvement of orexin-A. Front. Physiol. 8, 85 (2017).

126. Firth, J., Cotter, J., Elliott, R., French, P. \& Yung, A. R. A systematic review and meta-analysis of exercise interventions in schizophrenia patients. Psychol. Med. 45, 1343-1361 (2015).

127. Pedersen, B. K. \& Saltin, B. Exercise as medicine - evidence for prescribing exercise as therapy in 26 different chronic diseases. Scan. J. Med. Sci. Sports 25, 1-72 (2015). 